\title{
Laboreal
}

Volume $7 \mathrm{~N}^{\circ} 1$ | 2011

Psicodinâmica e psicopatologia do trabalho

\section{Relato de uma experiência de terreno de intervenção em Psicodinâmica do Trabalho (PDT)}

Informe de un estudio de campo sobre una intervención basada en la Psicodinámica del Trabajo (PDT)

Retour sur une expérience de terrain de l'intervention en psychodynamique du travail (PDT)

A field experience in the domain of psychodynamics of work

\section{Valérie Ganem}

Tradutor. Raúl Caeiro

\section{CpenEdition}

\section{Journals}

\section{Edição electrónica}

URL: http://journals.openedition.org/laboreal/8304

DOI: 10.4000/laboreal.8304

ISSN: 1646-5237

\section{Editora}

Universidade do Porto

\section{Refêrencia eletrónica}

Valérie Ganem, « Relato de uma experiência de terreno de intervenção em Psicodinâmica do Trabalho (PDT) », Laboreal [Online], Volume $7 N^{0} 1$ | 2011, posto online no dia 01 julho 2011, consultado o 10 outubro 2019. URL : http://journals.openedition.org/laboreal/8304; DOI : 10.4000/laboreal.8304

Este documento foi criado de forma automática no dia 10 outubro 2019.

Laboreal está licenciado com uma Licença Creative Commons - Atribuição-NãoComercial 4.0 Internacional. 


\section{Relato de uma experiência de terreno de intervenção em Psicodinâmica do Trabalho (PDT)}

Informe de un estudio de campo sobre una intervención basada en la Psicodinámica del Trabajo (PDT)

Retour sur une expérience de terrain de l'intervention en psychodynamique du travail (PDT)

A field experience in the domain of psychodynamics of work

\section{Valérie Ganem}

Tradução : Raúl Caeiro

\section{NOTA DO EDITOR}

Manuscrito recebido em : Outubro/2010

Aceite após peritagem em : Março/2011

\section{Introdução}

1 Aquando do $6^{0}$ Colóquio de Psicodinâmica e de Psicopatologia do Trabalho que se realizou pela primeira vez fora das fronteiras francesas, em São Paulo, entre 21 e 23 de Abril de 2010, as questões dos métodos e das técnicas foram longamente debatidas e várias divergências surgiram em função das origens geográficas ou profissionais daqueles que praticam estas disciplinas. Foi colocada a questão do pedido: podemos considerar que existe verdadeiramente um pedido proveniente do terreno quando um inquérito é realizado a pedido do Governo ou de um Sindicato ? Como avaliar o pedido nestas condições ? Como garantir o anonimato aos participantes? Como proceder quando quem formula o pedido deseja entrevistas individuais? Qual é o estatuto da 
aç̧ão em Psicodinâmica do Trabalho (PDT) ? Que resultados esperar de um inquérito ? Porque é necessário evitar realizar acompanhamentos, apesar de os actores do terreno frequentemente os pedirem?

Hoje, parece-me oportuno recordar a minha experiência de mais de vinte anos na qualidade de interveniente nos meios de trabalho em Gadalupe [1]. Tratar-se-á de relembrar essa experiência e de analisar as lições que dela pude tirar. Sublinharei num primeiro momento os princípios que me parecem actualmente fundamentais no quadro de uma intervenção em Psicodinâmica do Trabalho, as excepções possíveis a esses princípios e as suas consequências. Depois, apresentarei as numerosas dificuldades que se apresentam no quadro deste tipo de intervenção e os resultados que da mesma podem ser esperados.

\section{Histórico profissional}

\section{I.1 Uma experiência inicial de formadora}

3 Quando iniciei o meu percurso profissional em Guadalupe, eu era formadora. Rapidamente as teorias e os métodos da Psicodinâmica do Trabalho (PDT) me pareceram pertinentes para intervir nos meios de trabalho daquela ilha, na qual as relações sociais são particularmente duras. Eu intervinha, na altura, segundo um quadro metodológico do tipo formação-acção inspirado por contributos da PDT.

4 Começava as minhas acções por exposições teóricas sobre temas como as condições favoráveis à mobilização da inteligência no trabalho, a cooperação, a resistência à mudança ou ainda a avaliação do trabalho. Esses contributos teóricos eram seguidos de debates de tipo clínico sobre as dificuldades sentidas pelo grupo envolvido no seu trabalho. Após essa primeira etapa, tratava-se de definir os indicadores qualitativos que se supunha permitirem medir e/ou observar se o trabalho foi realizado de acordo com as regras comuns aos diferentes membros do grupo. Para terminar, propunha aos participantes que realizassem simulações filmadas das situações mais difíceis que tinham evocado. Isto, a fim de melhor se dar conta da operacionalidade dos indicadores retidos. Realizava estas acções sozinha.

5 Após vários anos de experiência, enquanto prosseguia os meus estudos de Psicologia do Trabalho, pude aperceber-me de que esta abordagem não era satisfatória. Aquilo que mais interesse tinha, afinal, no quadro deste dispositivo que tinha como objectivo compreender as dificuldades do trabalho, eram os debates de tipo clínico. As exposições teóricas arriscavam-se a influenciar o grupo na sua análise da situação, os indicadores não permitiam senão uma análise muito sumária do trabalho e as situações filmadas revelaram-se mais lúdicas do que úteis para compreender a situação, devido ao facto de os cenários evocados estarem muito distantes da realidade que se apresenta sempre de forma inesperada. $\mathrm{O}$ facto de conduzir essas acções sozinha também provou ser muito pesado e difícil.

\section{I.2 Uma experiência mais de acordo com a PDT}

6 Após cuidadosa reflexão, decidi rever esta abordagem e realizar os inquéritos de PDT como mandam as regras. A minha experiência mostrou-me que os princípios 
enunciados por esta disciplina se revelam muitas vezes incontornáveis para lidar com questões tão delicadas quanto a subjectividade, o sofrimento ou o prazer no trabalho.

7 Se nos referimos à definição de um método, encontramos num dicionário comum (Larousse 2009) : " conjunto de procedimentos, de meios para alcançar um resultado». O método de intervenção serve de guia ao praticante. Em Psicodinâmica do Trabalho é de acordo comum que todo o corpo teórico é colocado em questão a cada intervenção. Quer dizer que aquilo que acontece durante o inquérito, e que é sempre inesperado, pode colocar em causa a teoria e, portanto, o método. Assim, o terreno poderia, a cada inquérito, conduzir a um questionamento deste último. Ora, na adenda 1993 da obra "Travail : usure mentale ", Dejours constata: "Esta metodologia foi testada e, no essencial, não é útil submetê-la a modificações importantes ».

8 Globalmente, o método de inquérito em PDT pode resumir-se da seguinte forma : a intervenção começa por um pré-inquérito que consiste em encontrar uma formulação adequada do pedido, visitar os locais de trabalho e obter todos os documentos úteis respeitantes à organização em questão, bem como aos conflitos que marcaram a sua história.

9 O inquérito passa sempre pela constituição de pequenos grupos. Tal constituição obedece às categorias subjectivas definidas pelos intervenientes : o pedido e o seu conteúdo definem o grupo estudado. Os grupos são consituídos por voluntários, os quais se identificam a partir de uma reunião de informação na qual os intervenientes apresentam a intervenção a todo o pessoal. Os grupos assim constituídos participam em sessões colectivas de reflexão de meio dia de duração. Cada grupo reúne-se à razão de 2 a 4 sessões com um intervalo de 15 dias entre cada sessão. 0 material recolhido será depois reportado aos empregados numa sessão de um dia de duração consagrada à devolução oral. A leitura do relatório “ palavra por palavra » será objecto de discussões até ser validado pelos participantes e pelos intervenientes. Os participantes são os primeiros destinatários desse relatório. Por fim, o relatório servirá de quadro de referência às discussões ulteriores visando a transformação da organização do trabalho (Molinier, 2001).

Dentre os princípios metodológicos da PDT, provou-se que alguns eram mais determinantes e incontornáveis do que outros e tentaremos demonstrar em quê, à medida que os enunciamos, abaixo.

a. O trabalho do pedido : Trata-se de não nos contentarmos com o primeiro pedido que nos é formulado, quer este provenha da Direcção ou dos Sindicatos. É necessário submetê-lo aos diferentes actores implicados que são as instâncias representativas do pessoal, os médicos do trabalho, as assistentes sociais do pessoal e os próprios trabalhadores. Dominique Dessors, com a qual tive a oportunidade de tanto partilhar, dizia : "Não devemos fazer aquilo que nos pedem ». 0 pedido deve consistir, por exemplo, num pedido de compreensão da situação de trabalho, da maneira como os trabalhadores se colocam à prova dessa realidade, do destino do seu sofrimento e da sua relação subjectiva com o trabalho. 0 pedido deve visar uma investigação colectiva.

b. O voluntariado : Este aspecto faz parte do trabalho do pedido. Se não existem voluntários entre os trabalhadores implicados na situação de trabalho sobre a qual deve debruçar-se o inquérito, o mesmo não pode ter lugar. À excepção da informação legítima sobre a intervenção por meio de inquérito e o pedido que a sustenta, qualquer aç̧ão que vise incitar os trabalhadores, de uma maneira ou de outra, a voluntariarem-se, deve ser proibida. Isto, mesmo que o inquérito tenha uma razão de ser do ponto de vista científico ou do ponto de vista da Direcção ou ainda dos Sindicatos ou de quaisquer outros actores não directamente 
implicados. Apenas as pessoas que tomaram a iniciativa de se inscreverem são considerados como voluntários.

c. Esta é uma condição sine qua non da palavra autêntica e da escuta arriscada que devem poder existir nesses espaços de discussão. É igualmente indispensável se desejamos que os membros do grupo se possam exprimir quanto a matérias tão íntimas quanto a relação subjectiva com o trabalho ou o sofrimento no trabalho. Já aconteceu, por exemplo, os quadros ou os colegas pretenderem inscrever pessoas ausentes das reuniões de informação mas isso constitui, para mim, uma infracção inaceitável a este princípio.

d. Tamanho do grupo: 15 pessoas no máximo. Para além desse número, as condições necessárias à deliberação já não estão reunidas, tanto do lado da escuta quanto da palavra, e a gestão dos debates torna-se muito difícil. Este princípio, contrariamente ao precedente, pode ser infringido. Já trabalhei com um grupo de um pouco mais de 20 pessoas. Mas isso é totalmente desaconselhado quando é possível proceder de modo diferente e em particular para os praticantes menos experientes. A possibilidade de tirar à sorte quem participará no grupo de inquérito e uma restituição aos outros parece-me, nesse caso, uma boa alternativa.

e. Dois intervenientes no mínimo: Este princípio foi promulgado desde o início e revela-se bastante determinante no terreno. Permite não tomar sobre si todo o sofrimento e os conflitos evocados pelo grupo e ajuda a enfrentar as relações de poder e às vontades de instrumentaliazação das quais somos quase inevitavelmente objecto no contexto deste tipo de inquérito. Este risco existe de todas as partes. Do lado das Direcções, que podem pretender desta forma mostrar aos parceiros sociais que se preocupam com as questões de saúde no trabalho, não tendo qualquer intenção de questionar a sua organização do trabalho. Do lado dos Sindicatos, que podem pretender desse modo mostrar aos trabalhadores que são sensíveis aos seus problemas, desejando utilizar o inquérito para se fazerem valer no momento das eleições, sem estarem preparados para lutarem pela melhoria das situações de trabalho. Além disso, analisar a situação por diversos intervenientes permite igualmente evitar interpretações demasiado pessoais, frequentes quando lidamos com questões tão subjectivas. Os conflitos de interpretação que nascem dos debates no grupo de intervenientes são frequentemente reveladores dos conflitos existentes no grupo de inquérito e, portanto, úteis para a compreensão da situação. O outro interveniente deve, no entanto, estar sensibilizado para a PDT. É por isso que intervenho principalmente com médicos do trabalho ou antigos estudantes. Muitos intervenientes tiveram de intervir sozinhos para se adaptarem ao terreno. No entanto, todos o lamentaram e todos sublinharam a que ponto este princípio era útil e necessário tanto para a qualidade do trabalho de análise, quanto para a ética do praticante.

f. Não misturar níveis hierárquicos : O facto de coexistirem dentro de um mesmo grupo de inquérito pessoas de níveis hierárquicos diferentes constitui um problema para a qualidade da palavra e da escuta. Cada pessoa de um dado nível hierárquico sentir-se-á desconfortável ao exprimir de maneira autêntica as suas dificuldades face a alguém que é seu subalterno ou que é seu superior. Se há entre os voluntários pessoas de níveis hierárquicos diferentes, será preciso constituir mais grupos. Este é sem dúvida o princípio que mais debate suscita entre os praticantes. Por vezes é necessário, por exemplo, constituir um grupo de inquérito a partir de uma equipa de trabalhadores composta por membros cujos estatutos são muito heterogéneos - penso, por exemplo, numa equipa de cuidadores de um estabelecimento de saúde. Nesse caso, coexistem médicos, psicólogos, enfermeiros, auxiliares de acção médica, pessoal auxiliar de cuidados de saúde... que de forma alguma se posicionam ao mesmo nível hierárquico dentro da instituição. Pode, portanto, ser necessário reunir estes actores apesar de tudo, e não o fazer poderá mesmo condicionar a compreensão da situação de trabalho. No entanto, continuo a pensar que o enquadramento superior, por exemplo, ou a chefia do serviço, não deveria figurar em tal grupo se pretendemos que todos possam exprimir-se livremente, o que é uma condição sine qua non ao bom andamento do inquérito. 
g. Os participantes representam-se a si próprios : Este ponto parece-me muito importante para os representantes do pessoal, nomeadamente, que, quando eleitos, podem sentir-se capazes de falar pelos seus colegas. Ora, a relação subjectiva com o trabalho é sempre singular, o sofrimento, em particular, é sempre invisível e é por isso absolutamente impossível de ser expresso por procuração. Assim, os representantes do pessoal são sempre benvindos, desde que sejam voluntários, mas devem compreender desde o início que estão ali para falar unicamente em seu nome. Da mesma forma, parece-me difícil de entender que os trabalhadores, membros de um " comité de pilotage " [2], possam ir inquirir junto dos seus colegas para mais bem compreender a sua relação subjectiva com o trabalho. Uma infracção a este princípio parece-me decididamente problemática do ponto de vista da qualidade do material clínico desse modo recolhido. Não me parece que as precauções éticas a ter no contexto da recolha desse tipo de material estejam reunidas nesse caso e isso poderá ser perigoso para os trabalhadores que exprimiriam assim o seu sofrimento a um colega fora do quadro metodológico adequado ao inquérito.

h. $\underline{0}$ relatório é validado pelo grupo, pois este é o seu primeiro destinatário : O relatório redigido a propósito destas investigações é sistematicamente validado pelos participantes, e estes deverão ser sistematicamente os seus primeiros destinatários e decisores quanto à sua difusão. Este procedimento constitui a validação dos resultados do inquérito e parece, por isso, ser igualmente incontornável. Durante a investigação, o pedido final é submetido à reflexão do grupo ; nenhum questionário pré-estabelecido é submetido ao grupo. 0 objectivo é instaurar as condições de uma partilha autêntica através da presença de pelo menos dois intervenientes, exteriores ao contexto, especializados em Psicologia do Trabalho. Os intervenientes agem sobre dois eixos:

- Eixo 1 : Animar os debates entre os participantes, estimular a sua reflexão por meio de um questionamento de tipo clínico que não se contenta com aquilo que é enunciado mas leva o(s) interlocutor(es) a reflectir sobre o sentido da sua conduta e/ou das suas análises.

- Eixo 2: Alimentar a reflexão dos participantes através dos elementos técnicos e teóricos da Psicodinâmica do Trabalho.

11 Mas estes princípios são a prescrição, a sua aplicação gera sempre um certo número de dificuldades concretas que serão abordadas agora. Assim, os resultados que podemos esperar deste tipo de intervenção são, ao fim e ao cabo, ainda bastante modestos.

\section{Dificuldades e resultados esperados do inquérito de PDT}

\section{II.1 As dificuldades práticas de cumprimento destes princípios metodológicos}

12 A minha experiência de terreno mostrou-me que é sempre difícil encontrar um terreno comum em relação ao pedido. Este pode revestir-se de formas muito diferentes consoante os diferentes interlocutores (Direcção, representantes do pessoal, Médico do Trabalho, Assistente Social, trabalhadores...).

13 Notei também que a Direcção, os Sindicatos, e até os trabalhadores, podem pressionarnos para renunciarmos à nossa abordagem colectiva, no sentido de realizarmos entrevistas individuais, menos problemáticas, mais susceptíveis, segundo eles, de permitir a cada um exprimir-se livremente... Convencê-los de que uma abordagem colectiva é imperativa neste domínio da relação subjectiva com o trabalho pode revelar-se muito difícil. Similarmente, quem faz o pedido e os voluntários podem 
incitar-nos a realizarmos observações em situação de trabalho. Após reflexão, considero que tais observações devem ter lugar antes das reuniões, elas constituem aquilo que Dejours considera o pré-inquérito e permitem sentir o ambiente de trabalho, bem como aceder a uma certa subjectividade quando os trabalhadores vierem a evocar a sua experiência vivida. No que concerne às entrevistas individuais, admito ter por vezes acedido a tal pedido, se o mesmo era insistente e emanava dos voluntários. Por vezes, as relações dentro do grupo estão de tal forma degradadas que esta etapa, que pode também ser considerada como constitutiva do pré-inquérito, pode revelar-se útil. Ela permite a cada um "desabafar ", embora o essencial seja sobretudo não redigir nenhum relatório relativo a esta étapa e não ficar por aí, mas considerar estas entrevistas como uma fase preliminar da investigação colectiva.

Uma vez decidida a intervenção, no momento do primeiro encontro com o grupo, o princípio é reler o pedido formalizado e aguardar os comentários dos participantes. Nessa altura, frequentemente se instala um silêncio muito pesado que é preciso suportar. 0 erro aqui seria propor uma primeira interpretação que poderia influenciar, ou seja, deturpar, a análise realizada pelo grupo. A experiência mostrou-me que isto não é fácil e pude constatar várias vezes que, designadamente, os Médicos do Trabalho, eram tentados a falar para não continuarem a suportar o silêncio.

essões seguintes, vimos, no referido colóquio, que as práticas diferiam em função dos intervenientes. Alguns fazem relatórios intermédios, outros uma síntese oral da sessão anterior... Quando debatíamos este assunto com Dominique Dessors, ela dizia sempre que não devíamos fazer esse tipo de recordatório, fosse de que forma fosse. Para ela, era necessário voltar a enfrentar o silêncio, perguntando, por exemplo, ao grupo em que ponto tínhamos ficado na última vez. Ela considerava que era sempre interessante notar o tema pelo qual o grupo decidiria começar, esse era para ela um elemento essencial da análise.

Duma forma geral, neste tipo de intervenção, o tempo é incerto. Pode acontecer um inquérito desenrolar-se muito tempo após (por vezes mais de um ano) a primeira formulação do pedido. Muito frequentemente, também, os planeamentos dos encontros são alterados... Em retrospectiva, parece-me que este aspecto é inerente a esta abordagem, é preciso saber seguir o ritmo das organizações nas quais intervimos e levar em conta esse dado na análise que fazemos, sem pretender lutar contra o mesmo.

Sem dúvida o mais difícil deste trabalho, e que eu própria ainda luto para conseguir fazer, é não se contentar com a devolução da queixa, mas levar também os trabalhadores a compreenderem :

- O impacto psicológico da situação de trabalho sobre eles (o sofrimento, as defesas...),

- A sua responsabilidade na situação - Porque não fizeram eles tudo o que podiam para melhorarem a organização do trabalho, por exemplo?

- 0 sentido que tem a sua conduta bem como a dos outros.

Parece-me igualmente difícil não se fazer a devolução aos trabalhadores daquilo que seria desejável considerar para melhorar a situação. Eu venho da área da formação e da consultoria, na qual as recomendações constituem o essencial do trabalho, pelo que permanecer numa abordagem compreensiva é problemático para mim. Pude constatar que também o era muitas vezes para o grupo e para quem formula o pedido. Para ter em conta os imperativos da abordagem compreensiva ao mesmo tempo que estas expectativas dos nossos interlocutores, escolhi aproveitar a intervenção para recolher as pistas de acção consideradas pelo grupo a partir da nova compreensão da situação à 
qual o mesmo acedeu através do inquérito. Estas pistas são formuladas pelo grupo e não são portanto, em nada, as recomendações próprias de uma abordagem por um perito.

A redacção do relatório constitui igualmente uma real dificuldade neste trabalho. É sempre árduo e arriscado passar do momento do debate oral para o da escrita. E preciso admitir que não podemos escrever à primeira um documento que será integralmente validado. O tempo passado a retomar a escrita que propomos ao grupo faz parte integrante da abordagem. Pude notar que este trabalho era tanto mais difícil, demorado e fastidioso quanto mais nós tínhamos de lidar com interlocutores de posições elevadas na hierarquia. Num Banco, por exemplo, tivemos de passar 4 meios dias unicamente a validar o relatório do grupo Quadros. Penso que é um trabalho muito arriscado para os trabalhadores com essas funções, dos quais esperamos muitas vezes um discurso em perfeita adequação com o discurso da Direcção.

Quando realizo este tipo de intervenção, desejo que a Direç̧ão e a Gerência estejam cientes da realidade do trabalho e do seu impacto na saúde dos trabalhadores que têm sob sua responsabilidade. Isto, com o intuito de que ponham em marcha uma estratégia que coloque realmente o factor humano no centro da organização, e que este não seja apenas um slogan nos planos de comunicação das empresas. No terreno, isto revela-se quase impossível. Mesmo quando as Direcções acolhem positivamente os relatórios dos inquéritos, em última instância, é doloroso constatar como é raro obervar mudanças reais na organização do trabalho.

\section{II.2 Os resultados a esperar}

Quando intervimos em PDT é preciso portanto ser modesto em relação aos resultados a esperar. Atendendo à minha experiência, o que de melhor podemos esperar, no meu entender, é :

a. Uma melhor compreensão da situação de trabalho e do seu impacto na saúde e nas condutas dos trabalhadores, por parte dos diferentes actores da empresa, por meio das linhas que constituem o(s) relatório(s);

b. Uma estruturação e uma profissionalização em termos da saúde no trabalho das instâncias representativas do Pessoal e do Gabinete de Higiene, Segurança e das Condições do Trabalho, em particular ;

c. Uma restauração da capacidade de diálogo do grupo. Quando sabemos do carácter fundamental da existência de um espaço de discussão no seio de um grupo para a saúde no trabalho, este aspecto não é negligenciável ;

d. A modificação da organização do trabalho no sentido de uma melhor relação saúde-trabalho (abertura de espaços de discussão, melhor consideração do trabalho nas avaliações, modificação das regras e das suas aplicações...) Mas este resultado é raro e pressupõe uma luta muito dura dos grupos e/ou das instâncias representativas do Pessoal implicados.

\section{Conclusão}

Após todos estes anos de intervenção e todos os debates aos quais pude assistir, quer seja no Laboratório do CNAM [ $\left.{ }^{3}\right]$ dirigido por Christophe Dejours $\left[{ }^{4}\right]$ ou por ocasião dos 
diversos Colóquios Internacionais de Psicodinâmica e de Psicopatologia do Trabalho, parece-me que várias questões permanecem sem resposta :

- Um inquérito de PDT pode constituir uma forma de prevenção ? Em França, a Prevenção dos Riscos Psicossociais “ está na moda » e poderíamos ter a tentação de " ocupar o lugar » para que outros intervenientes menos despertos para a questão da saúde mental no trabalho o não ocupassem. Num debate sobre este tema no Laboratório, esta questão foi levantada. 0 que parece ser mais problemático para integrar uma tal abordagem é a questão da previsibilidade. Nós sabemos que não existe previsibilidade em Psicologia... Não podemos, por isso, pretender que a nossa acção possa constituir uma qualquer prevenção... Depois de muita discussão, naquele dia, Dominique Dessors concluíu repetindo o seu famoso "o que conta é não fazermos aquilo que nos pedem ». Com efeito, se o pedido que nos é formulado visa a prevenção, porque não trabalhar esse pedido para intervir de acordo com os nossos princípios ? Se nós não podemos garantir que este será um programa de prevenção, é uma aposta segura de que não será tão-pouco outro tipo de intervenção... A Segurança Social de Guadalupe lançou um concurso com o intuito de estabelecer protocolos com entidades que pudessem vir a tornar-se os interlocutores privilegiados das empresas locais em termos de intervenção ao nível dos riscos psicossociais. Respondi a esse concurso propondo uma abordagem que retomava exactamente a abordagem de inquérito da Psicodinâmica do Trabalho, mas sem a designar assim, e a minha proposta foi seleccionada.

- Um inquérito de PDT é uma intervenção ou uma investigação ? Mais uma vez, fazendo fé nas minhas discussões com Dominique Dessors, sou tentada a pensar que é sobretudo uma intervenção que deve responder a um pedido do terreno. Se é uma investigação comandada por patrocinadores públicos ou privados, como evitar que o grupo de voluntários seja instrumentalizado pelos investigadores e pelos seus patrocinadores para as suas necessidades, tão afastadas das dos voluntários?

Implementar um inquérito de PDT que respeite as regras do ofício revela-se portanto um trabalho muito difícil. É por isso que os praticantes devem manter-se vigilantes em relação aos princípios aqui inventariados, sobretudo tratando-se de estudantes. Caso contrário, o risco é de aos poucos a prática da PDT se ir degradando. Estes princípios foram desenvolvidos a partir de trinta anos de experiência a lidar com conceitos subtis tais como o sofrimento e o prazer no trabalho. Se perdemos de vista estes princípios arriscamo-nos a perder a capacidade de " agarrar » estas questões no terreno.

Quem mais nos incita a afastarmo-nos destes princípios são as Direcções das organizações, com o objectivo de mais bem nos instrumentalizarem. É, portanto, imperativo que não nos afastemos dos mesmos, tanto por uma preocupação de eficácia quanto por uma preocupação ética.

\section{BIBLIOGRAFIA}

Dejours, C. (2000). Travail, usure mentale. Paris : Fayard.

Dessors, D. (2009). De l'ergonomie à la PDT. Paris : Eres. 
Molinier, P. (2001). Souffrance et théorie de l'action ». Travailler. Revue internationale de psychopathologie et de psychodynamique du travail, $n^{\circ} 7$.

Molinier, P. (2006). Les enjeux psychiques du travail. Paris : Petite bibliothèque Payot.

\section{NOTAS}

1. Nota do Tradutor : Guadapule é uma região ultramarina francesa nas Caraíbas, constituída por dois arquipélagos : a "ilha de Guadalupe", na realidade composta por duas ilhas, Basse-Terre e Grande-Terre e ilhas próximas, e um grupo situado mais a Norte, constituído por São Bartolomeu, pela metade norte de São Martinho e ilhotas próximas. A capital é Basse-Terre.

2. Em psicodinâmica do trabalho, o termo de "comité de pilotage" designa um grupo de algumas pessoas (normalmente inclui os investigadores que intervêem, um representante da medicina do trabalho ou dos sindicatos, eventualmente alguém do departamento de recursos humanos da empresa...) constituido aquando da intervenção e que têm por objectivo conduzir o conjunto do processo (nomeadamente as questões logisticas como a escolha de horários para as reuniões, o local etc...).

3. N. do Tradutor : Conservatoire National des Arts et Métiers, estabelecimento de Ensino Superior tutelado pelo Governo francês, fundado em 1794, cujos objectivos são disponibilizar educação e conduzir investigação para a promoção da ciência e da indústria.

4. N. do Tradutor : A autora refere-se ao Laboratório de Psicologia do Trabalho e da Acção, dirigido por Christophe Dejours, no CNAM.

\section{RESUMOS}

Trata-se aqui de identificar, a partir de uma experiência de terreno, os princípios metodológicos que parecem fundamentais no quadro de uma intervenção em Psicodinâmica do Trabalho a fim de evitar os riscos de instrumentalização que ameaçam todos os praticantes desta disciplina. Depois, as dificuldades inerentes a este tipo de intervenção serão igualmente analisadas, tal como as questões que permanecem sem resposta e que concernem ao princípio de prevenção e ao estatuto destes inquéritos.

Nuestro propósito es identificar, a partir de un estudio de campo, los principios metodológicos que fueron fundamentales en el marco del desarrollo de una intervención basada en la Psicodinámica del Trabajo, con el objetivo de evitar el riesgo de instrumentalización que amenaza a los seguidores de esta disciplina. Igualmente, las dificultades inherentes a este tipo de intervención son analizadas, así como las preguntas que permanecen sin responder y que se vinculan al principio de prevención y al estatuto de estas investigaciones.

Il s'agit ici d'identifier, à partir d'une expérience de terrain, les principes méthodologiques qui apparaissent fondamentaux dans le cadre d'une intervention en psychodynamique du travail afin d'éviter les risques d'instrumentalisation qui guettent tout praticien de cette discipline. Ensuite les difficultés inhérentes à ce type d'intervention seront également analysées, ainsi que les questions qui restent en suspens concernant le principe de prévention et le statut de ces enquêtes. 
We aim to identify the methodological principles that seem to be crucial in a psychodynamics of work scenario, through a field experience, in order to avoid the risk of materialization that threatens all that adopt this subject. Next, we analyse the difficulties inherent to this type of intervention, such as the questions that remain unanswered associated to the prevention principle and to the status of these surveys.

ÍNDICE

Mots-clés: psychodynamique du travail, méthodologie, enquête, terrain

Palabras claves: psicodinámica del trabajo, metodología, investigación, estudio de campo

Keywords: psychodynamics of work, methodology, survey, field

Palavras-chave: psicodinâmica do trabalho, metodologia, inquérito, terreno

\section{AUTORES}

\section{VALÉRIE GANEM}

Mestre de Conferências na Universidade Paris 13 - Membro da Associação Internacional dos Especialistas de PDT, Université Paris XIII - IUT de Saint-Denis, Place du 8 mai 1945, 93206 SaintDenis

valerie.ganem1@orange.fr 